\title{
Research Paper: Molecular Analysis of rs2070744 and rs1799983 Polymorphisms of NOS3 Gene in Iranian Patients With Multiple Sclerosis
}

\author{
Mohammad Mehdi Heidari ${ }^{1 *}$, Mehri Khatami ${ }^{1}$, Yaser Tahamtan ${ }^{2}$ \\ 1. Department of Biology, Faculty of Science, Yazd University, Yazd, Iran. \\ 2. Department of Biology, Ashkezar Branch, Islamic Azad University, Yazd, Iran.
}

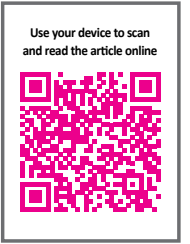

Citation: Heidari, M. M., Khatami, M, \& Tahamtan, Y. (2017). Molecular Analysis of rs2070744 and rs1799983 Polymorphisms of NOS3 Gene in Iranian Patients With Multiple Sclerosis. Basic and Clinical Neuroscience, 8(4), 279-284. https://doi. org/10.18869/NIRP.BCN.8.4.279

: https://doi.org/10.18869/NIRP.BCN.8.4.279

Article info:

Received: 13 Dec. 2016

First Revision: 12 Jan. 2017

Accepted: 05 May. 2017

\begin{abstract}
A B S T RA C T
Introduction: Multiple Sclerosis (MS) is a disease of central nervous system that mainly causes lesions or plaques in the spinal cord and brain. The purpose of this study was to analyze the relation between c.-813C $>$ T (rs2070744) and c.894G $>$ T (rs1799983) polymorphisms of NOS3 gene and MS in Iranian patients.

Methods: A total of 78 patients with MS and 80 healthy controls were screened for NOS3 (rs2070744 and rs1799983) Single Nucleotide Polymorphisms (SNPs) by tetra-primer multiplex ARMS-PCR and PCR-RFLP.

Results: Genotype frequencies of the c. $-813 \mathrm{C}>\mathrm{T}$ polymorphism in patients compared to controls were as follows: $53.8 \%$ to $80.0 \%$ for TT genotype, $41.0 \%$ to $18.8 \%$ for TC genotype, and $5.1 \%$ versus $1.2 \%$ for $\mathrm{CC}$ genotype $(\mathrm{P}=0.001)$. The frequencies of $\mathrm{GG}$ genotype was $57.7 \%$ and $78.8 \%$ and for GT genotype of c.894G $>$ T polymorphism in patients compared to control subjects was $42.3 \%$ and $21.2 \%$, respectively $(\mathrm{P}=0.004)$.
\end{abstract}

Conclusion: Our results indicate that the studied NOS3 polymorphisms may be associated with MS in Iranian patients.

\section{Introduction}

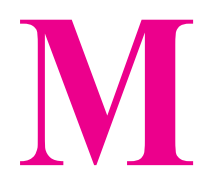

ultiple Sclerosis (MS) is a neuroimmunological disease, causing severe neurological disabilities as a result of demyelination (Goris, Pauwels, \& Dubois, 2012). It is mainly defined as a heterogeneous, complex, and multifactorial disease. The disease becomes progressive after several episodes in the majority of affected individu- als (Hoffjan \& Akkad, 2010; McElroy \& Oksenberg, 2011). Although twin and sibling pair studies point to a genetic component, the etiology of MS is mostly unknown. However, there is a seminal effort to detect the responsible genes in increased susceptibility and affecting clinical consequence (Hoffjan \& Akkad, 2010).

An important role for Nitric Oxide (NO) in the pathogenesis of MS and its influence on the various aspects of the disorder, including changes in synaptic transmis-

* Corresponding Author:

Mohammad Mehdi Heidari, PhD

Address: Department of Biology, Faculty of Science, Yazd University, Yazd, Iran.

Tel: +98 (35) 31233381

E-mail: Heidarimm@yazd.ac.ir 
sion, inflammation, and neuronal death were pointed by abundant evidence (Gerzanich, Ivanova, Zhou, \& Simard, 2003; Jagnandan, Sessa, \& Fulton, 2005). Several studies are shown that nitrate, NO degradation product, is found with increased concentration in cerebrospinal fluid of patients with MS (Giovannoni, 1998; Tajouri et al., 2004).

Oxidation of L-arginine to Nitric Oxide (NO) is catalyzed by Nitric Oxide Synthases (NOSs). An isoform of NO producing enzymes is endothelial Nitric Oxide Synthase (NOS3) that is constitutively expressed in endothelial cells. This enzyme has been found to play a prominent role in both vasculogenesis and angiogenesis. The nitric oxide synthases is encoded by NOS3 gene located on chromosome 7q35-q36 (Forstermann \& Sessa, 2011). There are two common polymorphisms of NOS3 gene in many populations that are associated with NOS3 enzyme activity and production. In the seventh exon of the NOS3 gene, the c.894G>T SNP substitutes glutamic acid at codon 298 to aspartic acid (Glu298Asp).

This polymorphism causes diminished NOS3 enzyme activity and the c.-813C $>$ T (rs2070744) polymorphism in the promoter region, where it has been found with reduced NOS3 promoter activity in vitro (Miyamoto et al., 1998; Veldman et al., 2002). The genetic association of these NOS3 gene polymorphisms and susceptibility to MS have identified in several studies (AlFadhli, Mohammed \& Al Shubaili, 2013; Blanco, Yague, Graus, \& Saiz, 2003; Modin et al., 2001; Tajouri et al., 2004). The purpose of the present research was to determine a relation between c. $-813 \mathrm{C}>\mathrm{T}$ (rs2070744) and c.894G $>$ T (rs1799983) polymorphisms of NOS3 gene with susceptibility to MS in Iranian population.

\section{Methods}

\subsection{Study subjects}

After a neurological examination, 78 patients with MS (60 females and 18 males) and the mean age of 33.74 years (age range from 24-57 years) were recruited from MS Clinic (Yazd, Iran). Healthy volunteers (80 subjects) were randomly selected from their families with no history of autoimmune and neurological diseases. In the present study, the experimental and control groups were ethnically matched. All individuals gave informed consent for DNA test. DNA extraction was performed from whole blood with salting out method according to the manufacturer's instructions. Patients and controls' blood and DNA samples were isolated and stored at $-20^{\circ} \mathrm{C}$.

\subsection{Genotyping of NOS3 (rs2070744) by Multi-} plex-ARMS PCR

Genotyping of c.-813C > T NOS3 SNP (rs2070744) was detected by tetra-primer ARMS-PCR (T-ARMSPCR). PCR amplification of c.-813C $>$ T polymorphism in the $5^{\prime}$ flanking region of the NOS3 gene was performed using four primers. The online website Primer1 was used for design of our primers (Table 1). The primers specificity were tested with 'BLAST' program in NCBI server. To improve the specificity of T-ARMSPCR, the 3rd nucleotide from the 3 '-terminus of inner primers was changed to destabilize mismatch.

PCR was achieved in $25 \mu \mathrm{L}$ volume, containing 50 ng of DNA, 1X PCR Master Mix, and $250 \mathrm{nM}$ of each primer (Yekta Tajhiz Azma, Tehran, Iran). Touchdown PCR was performed at $95^{\circ} \mathrm{C}$ for $2 \mathrm{~min}$, denaturation at $95^{\circ} \mathrm{C}$ for $20 \mathrm{~s}$, the first 10 cycles annealing temperature at $68^{\circ} \mathrm{C}$ to $60^{\circ} \mathrm{C}$ and remaining 25 cycles at annealing at $59^{\circ} \mathrm{C}$ for $60 \mathrm{~s}$ and extension at $72^{\circ} \mathrm{C}$ for $50 \mathrm{~s}$. The PCR products were run on $2 \%$ agarose gel electrophoresis. In this method, the gel electrophoresis revealed 3 bands in AG heterozygotes $(319,150$, and $211 \mathrm{bp}), 2$ bands in AA homozygotes (319 and $150 \mathrm{bp}$ ), and 2 bands in GG homozygotes (319 and $211 \mathrm{bp}$ ) (Figures 1 and 2).

\subsection{Genotyping NOS3 (rs1799983) by PCR-RFLP}

The NOS3 polymorphism c.894G $>\mathrm{T}$ introduces the restriction site for $\mathrm{MboI}$ endonuclease. PCR was achieved in $25 \mu \mathrm{L}$ volume; containing 50 ng of DNA, 1X PCR Master Mix, and $250 \mathrm{nM}$ of each primer (Yekta Tajhiz Azma, Tehran, Iran). The PCR reaction was according to the following stages: 35 cycles; including denaturation, annealing, and extension at $95^{\circ} \mathrm{C}, 64^{\circ} \mathrm{C}$, and $72^{\circ} \mathrm{C}$ for $35 \mathrm{~s}$, respectively; and a final extension at $72^{\circ} \mathrm{C}$ for $5 \mathrm{~min}$. According to Figure 2, a $292 \mathrm{bp}$ fragment was detected in GG homozygote genotypes (Mbol- undigested), also 197 and 95 bp fragments in TT homozygote genotypes (MboI- digested), finally 292, 197, and 95 bp fragments in GT heterozygote genotypes (MboI- digested and undigested fragments).

\subsection{Statistical analysis}

Statistical analysis was performed using SPSS (IBM SPSS 22, SPSS Inc., Chicago, IL., USA). Allelic and genotypic frequencies were calculated for each SNPs. Multiple logistic regression models (co-dominant, dominant, recessive, and over-dominant) were employed to analyze the genetic data. $\mathrm{P}$ value less than 0.05 was considered statistically significant. 


\section{Results}

The genotype distributions and allele frequencies of two types of polymorphism in NOS3 gene, c.-813C $>\mathrm{T}$, and c.894G $>$ T were analyzed in Iranian patients with MS and healthy controls. Table 2 presents genotypic and allelic frequencies of c. $-813 \mathrm{C}>\mathrm{T}$ polymorphism among the patients and controls group. In the patients group, the frequencies of TT, CT and CC genotypes were $53.84 \%, 41.02 \%$, and $5.1 \%$, respectively. In the control group, the frequencies of TT, CT, and CC genotypes were $80.0 \%, 18.8 \%$ and $1.2 \%$, respectively. Statistical analysis showed that c. $-813 \mathrm{C}>\mathrm{T}$ polymorphism is associated with risk of MS according to co-dominant, dominant, and over-dominant model (co-dominant model, $\mathrm{P}=0.001$; dominant model, $\mathrm{P}=0.004$; and overdominant, $\mathrm{P}=0.002$ ). The prevalence of $\mathrm{C}$ allele was significantly higher in patients compared to the control group (OR: 0.345, 95\%CI: 0.18-0.64; $\mathrm{P}=0.001$ ).

Genotypic and allelic frequencies of c. $894 \mathrm{G}>\mathrm{T}$ polymorphism among the patients and controls group were shown in Table 3. In the patients group, the frequencies of GG, GT, and TT genotypes were $57.7 \%, 42.3 \%$, and $0.0 \%$, respectively. In the control group, the frequencies of GG, GT, and TT genotypes were 78.7\%, 21.2\%, and $0.0 \%$, respectively. Statistical analysis showed that according to co-dominant model, c. $894 \mathrm{G}>\mathrm{T}$ polymorphism is associated with risk of $\mathrm{MS}(\mathrm{P}=0.004)$. The prevalence of $\mathrm{T}$ allele was significantly higher in pa-

Table 1. PCR primers and conditions.

\begin{tabular}{|c|c|c|c|}
\hline eNOS Gene & * Primer Sequence & Temperature & Amplicon Size \\
\hline \multirow{4}{*}{ SNP ID: rs2070744 } & F1: 5'-CTACAAACCCCAGCATGCACTC-3' & $66 \circ \mathrm{C}$ & \multirow{4}{*}{$\begin{array}{c}\text { T allele (150bp) } \\
\text { C allele (211bp) } \\
\text { Control band (319bp) }\end{array}$} \\
\hline & R1: 5'-CATTAGGGTATCCCTTCCCCTC-3' & $66 \circ \mathrm{C}$ & \\
\hline & F2: 5'-GGGCATCAAGCTCTTCCCTGTCC-3' & $72 \circ \mathrm{C}$ & \\
\hline & R2: 5'-TAGGGCTGAGGCAGGGTCAGACA-3' & $70 \circ \mathrm{C}$ & \\
\hline \multirow[t]{2}{*}{ SNP ID: rs1799983 } & F3: 5'-TCACGGAGACCCAGCCAATGAG-3' & $70 \circ \mathrm{C}$ & $\begin{array}{c}\text { G allele } \\
\text { Undigested with Mbol (293bp) }\end{array}$ \\
\hline & R3: 5'-TCCATCCCACCCAGTCAATCCC-3' & $70^{\circ} \mathrm{C}$ & $\begin{array}{c}\text { T allele } \\
\text { Digest with Mbol }(197+95 b p)\end{array}$ \\
\hline
\end{tabular}

* F1, F2, R1 and R2 primers designed for T-ARMS-PCR and F3 and R3 for PCR- RFLP reaction.

NEUR:SCIENCE

Table 2. Genotype counts and allele frequencies c.-813C >T (rs2070744) polymorphism in patients and controls.

\begin{tabular}{|c|c|c|c|c|c|}
\hline & Genotype/Allele & MS Patients $(n=78)$ & Healthy Controls $(n=80)$ & Odds Ratio (95\% Cl) & $\mathbf{P}$ \\
\hline \multirow{3}{*}{ Co-dominant model } & $\mathrm{TT}$ & $42(53.8 \%)$ & $64(80.0 \%)$ & 1 (ref.) & \multirow{3}{*}{0.001} \\
\hline & $\mathrm{TC}$ & $32(41.0 \%)$ & $15(18.8 \%)$ & $3.25(1.57-6.72)$ & \\
\hline & $\mathrm{CC}$ & $4(5.1 \%)$ & $1(1.2 \%)$ & $6.10(0.66-56.44)$ & \\
\hline \multirow{3}{*}{ Dominant model } & $\mathrm{TT}$ & $42(53.8 \%)$ & $64(80.0 \%)$ & \multirow{3}{*}{$3.43(1.69-6.95)$} & \multirow{3}{*}{0.004} \\
\hline & & & & & \\
\hline & $\mathrm{TC}+\mathrm{CC}$ & $36(46.2 \%)$ & $16(20.0 \%)$ & & \\
\hline \multirow{3}{*}{ Recessive model } & $\mathrm{TT}+\mathrm{TC}$ & $74(94.9 \%)$ & 79(98.8\%) & \multirow{3}{*}{$4.27(0.47-39.09)$} & \multirow{3}{*}{0.150} \\
\hline & & & & & \\
\hline & $\mathrm{CC}$ & $4(5.1 \%)$ & $1(1.2 \%)$ & & \\
\hline \multirow{3}{*}{ Over-dominant model } & $\mathrm{TT}+\mathrm{CC}$ & $46(59.0 \%)$ & $65(81.2 \%)$ & \multirow{3}{*}{$3.01(1.47-6.19)$} & \multirow{3}{*}{0.002} \\
\hline & & & & & \\
\hline & TC & $32(41.0 \%)$ & $15(18.8 \%)$ & & \\
\hline \multirow{3}{*}{ Allele frequency } & $\mathrm{T}$ & $116(74.4 \%)$ & $143(89.4 \%)$ & \multirow{3}{*}{$0.345(0.18-0.64)$} & \multirow{3}{*}{0.001} \\
\hline & & & & & \\
\hline & $\mathrm{C}$ & $40(25.6 \%)$ & $17(10.6 \%)$ & & \\
\hline
\end{tabular}


Table 3. Genotype counts and allele frequencies c.894G>T SNP (rs1799983) in patients and controls.

\begin{tabular}{|c|c|c|c|c|}
\hline Genotype/Allele & $\begin{array}{l}\text { MS Patients } \\
\quad(n=78)\end{array}$ & $\begin{array}{l}\text { Healthy Controls } \\
\qquad(n=80)\end{array}$ & $\begin{array}{c}\text { Odds Ratio } \\
(95 \% \mathrm{Cl})\end{array}$ & $\mathbf{P}$ \\
\hline Co-dominant model & $45(57.7 \%)$ & $63(78.8 \%)$ & 1 (ref.) & \\
\hline GG & & & & 0.004 \\
\hline GT & $33(42.3 \%)$ & $17(21.2 \%)$ & $2.72(1.35-5.47)$ & \\
\hline TT & $0(0.0 \%)$ & $0(0.0 \%)$ & & \\
\hline \multicolumn{5}{|l|}{ Allele frequency } \\
\hline G & $123(87.8 \%)$ & $143(89.4 \%)$ & & \\
\hline T & $33(21.2 \%)$ & $17(10.6 \%)$ & $0.443(0.23-0.83)$ & 0.013 \\
\hline
\end{tabular}

tients compared to the control group (OR: 0.443, 95\% CI: 0.23-0.83; $\mathrm{P}=0.013)$.

\section{Discussion}

The involvement of Nitric Oxide (NO) in MS had been suggested after the discovery of the critical role of NO in inflammation. However, due to the opposing roles of $\mathrm{NO}$ in cellular processes, the extent of $\mathrm{NO}$ contribution to MS is not yet fully understood. In this study, we found significant differences in the distribution of c. $-813 \mathrm{C}>\mathrm{T}$ and c.894G $>\mathrm{T}$ polymorphisms of the NOS3 gene in Iranian patients with MS compared with healthy population. Several reports have been showed that c. $-813 \mathrm{C}>\mathrm{T}$ (rs2070744) polymorphism in the $5^{\prime}$ flanking (promoter) region of the NOS3 gene is associated with coronary spasm and vascular disease (Casas et al., 2006; Kajiyama et al., 2000; Nakayama et al., 1999; Nakayama et al., 2000). Also, previous studies have demonstrated the association between this poly-

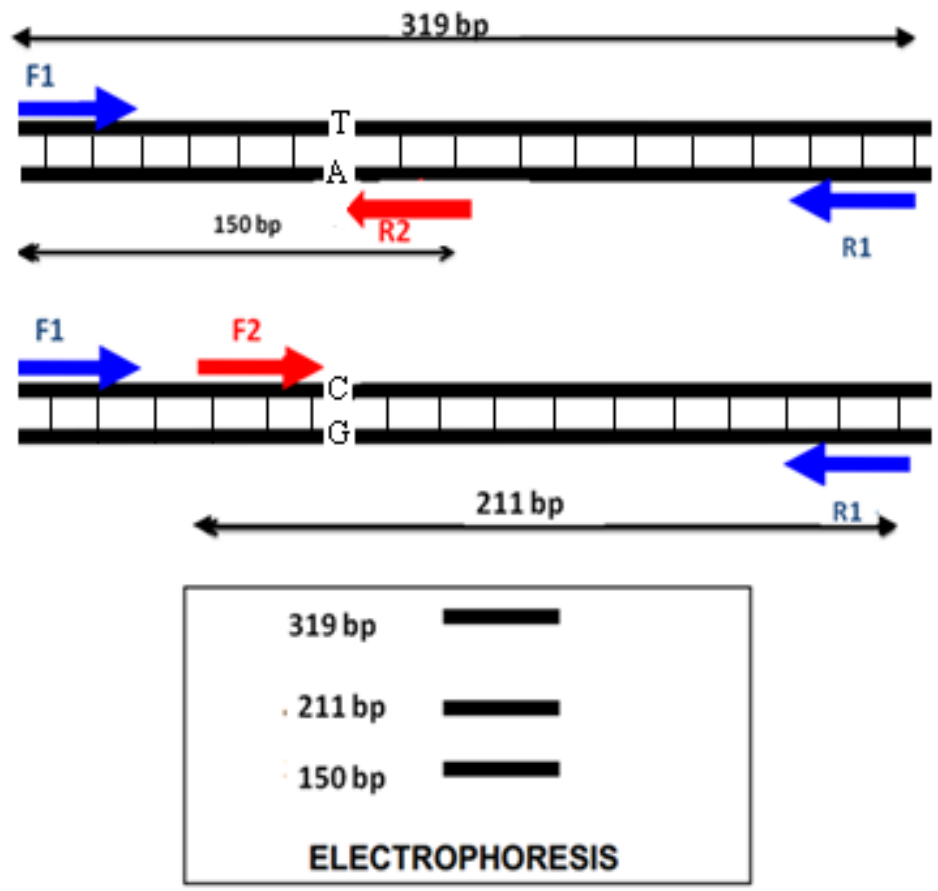

NEUROSCIENCE

Figure 1. Schematic presentation of T-ARMA-PCR technique for c.-813C $>$ T polymorphism detection. A larger (non-allelespecific) control amplicon and two different allele-specific amplicons are generated by a pair of two common (outer) primers and two allele specific (inner) primers. 
a)

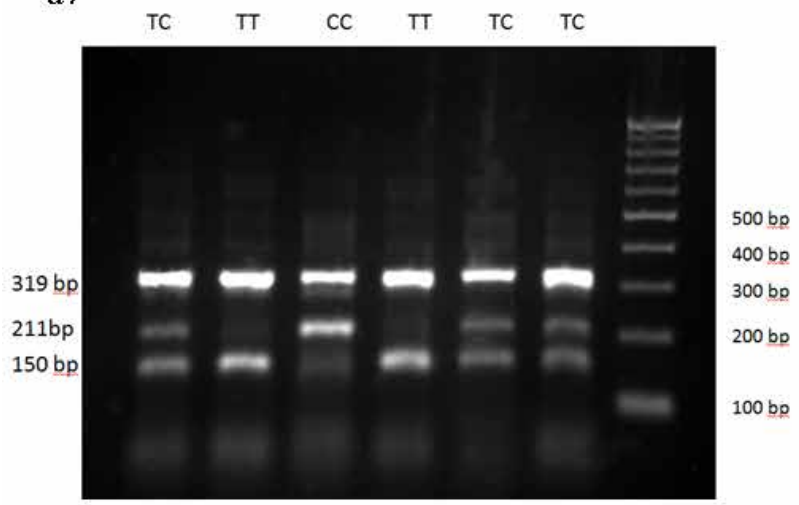

b)

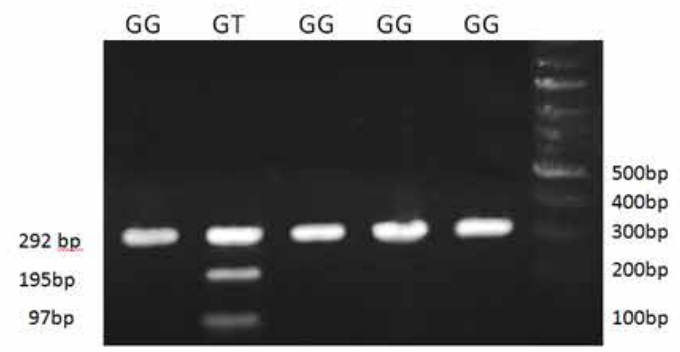

NEUR:SCIENCE

Figure 2. a) Results of T-ARMS-PCR of rs2070744 polymorphism and b) PCR-RFLP of rs1799983 by MboI restriction endonuclease.

morphism and recurrent abortions and male infertility (Luo et al., 2013; Safarinejad, Shafiei, \& Safarinejad, 2010). This SNP significantly reduces NOS3 promoter transcription activity, inhibiting NO production which ends in endothelial dysfunction. The present study demonstrated that this polymorphism was associated with the MS in Iranian population and might play an important role in our patients. The frequency of $\mathrm{C}$ allele in our patients was significantly higher than control subjects ( $\mathrm{P}=0.001)$. To our knowledge, the current research is the first to study the correlation of rs2070744 with MS. The physiological and pathological effects of c.-813C $>\mathrm{T}$ polymorphism, however, requires further research.

The present study is the first to reveal an association between the c.894G $>$ T SNP (rs1799983) of the NOS3 (Glu298Asp variant) gene and susceptibility to MS $(\mathrm{P}=0.004)$. We aimed to elucidate the missense Glu298Asp polymorphism within exon 7 of the NOS3 gene in 78 Iranian MS patients and 80 healthy controls. Some authors have suggested that Glu298Asp polymorphism in NOS3 gene plays a role in various diseases such as idiopathic male infertility, myocardial infraction, and placental abruption (Gad et al., 2012; Luo, Wen, Zhou, Chen, \& Zhang, 2014; Safarinejad et al., 2010; Yoshimura, Yoshimura, Tabata, Yasue, \& Okamura, 2001). The c.894G > T SNP alters the stability, biological halflife, and activity of the enzyme and is associated with reduced NO production (Wang et al., 1997).

Several findings have revealed that this mutation was the result of a conformational change in the eNOS protein from helix form to tight turn (Joshi, Mineo, Shaul, \& Bauer, 2007). Based on our expectation, the statistical difference in this SNP indicates the correlation of $\mathrm{G}$ allele of rs1799983 with MS patients compared with controls. Thus, $\mathrm{G}$ allele had the greatest effects in Iranian patients. Our results show that NOS3 polymorphisms may be associated with MS in Iranian patients and so these variants might influence the risk of MS, specifically in the Iranian population.

\section{Acknowledgments}

This research was financialy supported by Yazd University. The authors thank the patients for their cooperation as well as MS Clinic (Yazd, Iran) and Shahid Sadoughi University of Medical Sciences.

\section{Conflict of Interest}

The authors declared no conflicts of interest.

\section{References}

AlFadhli, S., Mohammed, E. M. A., \& AlShubaili, A. (2013). Association analysis of nitric oxide synthases: NOS1, NOS2A and NOS3 genes, with multiple sclerosis. Annals of Human Biology, 40(4), 368-375. doi: 10.3109/03014460.2013.786756

Blanco, Y., Yague, J., Graus, F., \& Saiz, A. (2003). No association of inducible nitric oxide synthase gene (NOS2A) to multiple sclerosis. Journal of Neurology, 250(5), 598-600. doi: $10.1007 / \mathrm{s} 00415-003-1047-7$

Casas, J. P., Cavalleri, G. L., Bautista, L. E., Smeeth, L., Humphries, S. E., \& Hingorani, A. D. (2006). Endothelial nitric oxide synthase gene polymorphisms and cardiovascular disease: A HuGE review. American Journal of Epidemiology, 164(10), 921-35. doi: 10.1093/aje/kwj302

Forstermann, U., \& Sessa, W. C. (2011). Nitric oxide synthases: Regulation and function. European Heart Journal, 33(7), 829_ 37. doi: 10.1093/eurheartj/ehr304 
Gad, M. Z., Abdel Rahman, M. F., Hashad, I. M., AbdelMaksoud, S. M., Farag, N. M., \& Abou-Aisha, K. (2012). Endothelial nitric oxide synthase (G894T) gene polymorphism in a random sample of the Egyptian population: Comparison with myocardial infarction patients. Genetic Testing and Molecular Biomarkers, 16(7), 695-700. doi: 10.1089/ gtmb.2011.0342

Gerzanich, V., Ivanova, S., Zhou, H., \& Simard, J. M (2003). Mislocalization of eNOS and upregulation of cerebral vascular $\mathrm{Ca}^{2+}$ channel activity in angiotensin-hypertension. Hypertension, 41(5), 1124-30. doi: 10.1161/01. HYP.0000066288.20169.21

Giovannoni, G. (1998). Cerebrospinal fluid and serum nitric oxide metabolites in patients with multiple sclerosis. Multiple Sclerosis Journal, 4(1), 27-30. doi: $10.1177 / 135245859800400107$

Goris, A., Pauwels, I., \& Dubois, B. (2012). Progress in multiple sclerosis genetics. Current Genomics, 13(8), 646-63. doi 10.2174/138920212803759695

Hoffjan, S., \& Akkad, D. A. (2010). The genetics of multiple sclerosis: An update 2010. Molecular and Cellular Probes, 24(5), 237-43. doi: 10.1016/j.mcp.2010.04.006

Jagnandan, D., Sessa, W. C., \& Fulton, D. (2005). Intracellular location regulates calcium-calmodulin-dependent activation of organelle-restricted eNOS. AJP: Cell Physiology, 289(4), 1024-33. doi: 10.1152/ajpcell.00162.2005

Joshi, M. S., Mineo, C., Shaul, P. W., \& Bauer, J. A. (2007). Biochemical consequences of the NOS3 Glu298Asp variation in human endothelium: Altered caveolar localization and impaired response to shear. The FASEB Journal, 21(11) 2655-63. doi: 10.1096/fj.06-7088com

Kajiyama, N., Saito, Y., Miyamoto, Y., Yoshimura, M., Nakayama, M., Harada, M., et al. (2000). Lack of association between T-786.RAR.C mutation in the $5^{\prime}$-flanking region of the endothelial nitric oxide synthase gene and essential hypertension. Hypertension Research, 23(6), 561-5. doi: 10.1291/ hypres. 23.561

Luo, J. Q., Wen, J. G., Zhou, H. H., Chen, X. P., \& Zhang, W. (2014). Endothelial nitric oxide synthase gene G894T polymorphism and myocardial infarction: A meta-analysis of 34 studies involving 21,068 subjects. PLOS ONE, 9, 87196. doi: 10.1371/journal.pone.0087196

Luo, L., Li, D. H., Wei, S. G., Zhang, H. B., Li, S. B., \& Zhao, J. (2013). Polymorphisms in the endothelial nitric oxide synthase gene associated with recurrent miscarriage. Genetics and Molecular Research, 12(3), 3879-86. doi: 10.4238/2013. september.23.6

McElroy, J. P., \& Oksenberg, J. R. (2011). Multiple sclerosis genetics 2010. Neurologic Clinics, 29(2), 219-31. doi: 10.1016/j. ncl.2010.12.002

Miyamoto, Y., Saito, Y., Kajiyama, N., Yoshimura, M., Shimasaki, Y., Nakayama, M., et al. (1998). Endothelial nitric oxide synthase gene is positively associated with essential hypertension. Hypertension, 32(1), 3-8. doi: 10.1161/01.hyp.32.1.3

Modin, H., Dai, Y., Masterman, T., Svejgaard, A., Sørensen, P. S., Oturai, A., et al. (2001). No linkage or association of the nitric oxide synthase genes to multiple sclerosis. Journal of Neuroimmunology, 119(1), 95-100. doi: 10.1016/s0165 5728(01)00366-6
Nakayama, M., Yasue, H., Yoshimura, M., Shimasaki, Y Kugiyama, K., Ogawa, H., et al. (1999). T-786 $\rightarrow$ C mutation in the $5^{\prime}$-flanking region of the endothelial nitric oxide synthase gene is associated with coronary spasm. Circulation 99(22), 2864-70. doi: 10.1161/01.cir.99.22.2864

Nakayama, M., Yasue, H., Yoshimura, M., Shimasaki, Y., Ogawa, H., Kugiyama, K., et al. (2000). T-786 $\rightarrow$ C mutation in the 5 '-flanking region of the endothelial nitric oxide synthase gene is associated with myocardial infarction, especially without coronary organic stenosis. The American Journal of Cardiology, 86(6), 628-34. doi: 10.1016/s0002-9149(00)01041-9

Safarinejad, M. R., Shafiei, N., \& Safarinejad, S. (2010). The role of endothelial nitric oxide synthase (eNOS) T-786C, G894T, and $4 \mathrm{a} / \mathrm{b}$ gene polymorphisms in the risk of idiopathic male infertility. Molecular Reproduction and Development, 77(8), 720-7. doi: $10.1002 / \mathrm{mrd} .21210$

Tajouri, L., Ferreira, L., Ovcaric, M., Curtain, R., Lea, R., Csurhes, P., et al (2004). Investigation of a neuronal nitric oxide synthase gene (NOS1) polymorphism in a multiple sclerosis population. Journal of the Neurological Sciences, 218(1-2), 25-8. doi: 10.1016/j.jns.2003.10.006

Veldman, B. A., Spiering, W., Doevendans, P. A., Vervoort, G., Kroon, A. A., de Leeuw, P. W., et al. (2002). The Glu298Asp polymorphism of the NOS 3 gene as a determinant of the baseline production of nitric oxide. Journal of Hypertension 20(10), 2023-7. doi: 10.1097/00004872-200210000-00022

Wang, X. L., Mahaney, M. C., Sim, A. S., Wang, J., Wang, J., Blangero, J., et al. (1997). Genetic contribution of the endothelial constitutive nitric oxide synthase gene to plasma nitric oxide levels. Arteriosclerosis, Thrombosis, and Vascular Biology, 17(11), 3147-53. doi: 10.1161/01.atv.17.11.3147

Yoshimura, T., Yoshimura, M., Tabata, A., Yasue, H., \& Okamura, H. (2001). The missense Glu298Asp variant of the endothelial nitric oxide synthase gene is strongly associated with placental abruption. Human Genetics, 108(3), 181-3. doi: $10.1007 /$ s004390000454 